See discussions, stats, and author profiles for this publication at: https://www.researchgate.net/publication/316857478

Ultrasonic assisted creep feed grinding of gamma titanium aluminide using conventional and superabrasive wheels

Article in CIRP Annals - Manufacturing Technology · August 2017

DOI: $10.1016 /$ j.cirp.2017.04.085

CITATION

1

7 authors, including:

Debajyoti Bhaduri

Cardiff University

30 PUBLICATIONS 223 CITATIONS

SEE PROFILE
Stefan Bohr

Saint-Gobain

14 PUBLICATIONS 435 CITATIONS

SEE PROFILE

Some of the authors of this publication are also working on these related projects:

Ecoject Ecolaserfact View project

Project Hyproline View project 


\section{UNIVERSITYOF BIRMINGHAM \\ University of Birmingham Research at Birmingham}

\section{Ultrasonic assisted creep feed grinding of gamma titanium aluminide using conventional and superabrasive wheels}

Bhaduri, Debajyoti; Soo, Sein; Aspinwall, David; Novovic, Donka; Bohr, Stefan; Harden, Peter; Webster, John A.

DOI:

10.1016/j.cirp.2017.04.085

License:

Creative Commons: Attribution-NonCommercial-NoDerivs (CC BY-NC-ND)

Document Version

Peer reviewed version

Citation for published version (Harvard):

Bhaduri, D, Soo, S, Aspinwall, D, Novovic, D, Bohr, S, Harden, P \& Webster, JA 2017, 'Ultrasonic assisted creep feed grinding of gamma titanium aluminide using conventional and superabrasive wheels' CIRP Annals Manufacturing Technology, vol 66, no. 1, pp. 341-344. DOI: 10.1016/j.cirp.2017.04.085

Link to publication on Research at Birmingham portal

\section{General rights}

When referring to this publication, please cite the published version. Copyright and associated moral rights for publications accessible in the public portal are retained by the authors and/or other copyright owners. It is a condition of accessing this publication that users abide by the legal requirements associated with these rights.

- You may freely distribute the URL that is used to identify this publication.

- Users may download and print one copy of the publication from the public portal for the purpose of private study or non-commercial research.

- If a Creative Commons licence is associated with this publication, please consult the terms and conditions cited therein.

- Unless otherwise stated, you may not further distribute the material nor use it for the purposes of commercial gain.

\section{Take down policy}

If you believe that this document infringes copyright please contact UBIRA@lists.bham.ac.uk providing details and we will remove access to the work immediately and investigate. 


\title{
Ultrasonic assisted creep feed grinding of gamma titanium aluminide using conventional and superabrasive wheels
}

\author{
Debajyoti Bhaduri a, Sein Leung Soo (2)a, David K. Aspinwall (1) ${ }^{a,}{ }^{*}$, Donka Novovic b, Stefan Bohr c, \\ Peter Harden a,1, John A. Webster (1) ${ }^{\mathrm{d}}$ \\ a Machining Research Group, Department of Mechanical Engineering, School of Engineering, University of Birmingham, Edgbaston, Birmingham, B15 2TT, UK \\ ${ }^{b}$ Manufacturing Technology, Global Manufacturing Centre, Rolls-Royce plc, Derby, DE24 8ER, UK \\ c Saint-Gobain Diamantwerkzeuge GmbH, Schützenwall 13-17, D-22844 Norderstedt, Germany \\ ${ }^{d}$ Cool-Grind Technologies, Ashford, Connecticut, 06278, USA \\ ${ }^{1}$ Previously at Element Six Ltd. at the time the research was performed
}

The paper details experimental work on ultrasonic assisted creep feed grinding (UACFG) of $\gamma$-TiAl intermetallic alloy: Ti-45Al-2Mn-2Nb+0.8vol.\%TiB $2 \mathrm{XD}$ (wt\%), using conventional SiC and electroplated diamond wheels. The majority of forces recorded were lower when using vibration assistance compared to conventional CFG by up to $\sim 35 \%$, while grinding-ratios for the superabrasive wheel were substantially higher by a factor of $2-7$. A reduction in workpiece surface roughness by up to $\sim 10 \%$ together with fewer defects and marginally increased subsurface microhardness by a maximum of $\sim 8 \%$, was obtained when employing ultrasonic assistance. With uprated process parameters however, the effects of UACFG were less apparent.

Titanium; vibration; surface integrity

\section{Introduction}

Despite the potential for gamma titanium aluminide ( $\gamma$-TiAl) intermetallic alloys to replace heavier nickel based superalloy components such as turbine and compressor blades in gas turbine aeroengines, few civil or military applications currently exist. Several factors are responsible, not least the lack of a comprehensive material supply base and the requirement for stringent safety standards, but also alloy sensitivity to secondary production/manufacturing methods and associated post processing costs [1]. Key conventional machining operations for blades include high speed milling and grinding, the latter proving less of a problem in terms of machinability and the generation of acceptable workpiece surface integrity, due in part to the low room temperature ductility $(\sim 2 \%)$ of many $\gamma$-TiAl alloys [2]. While several researchers have shown the feasibility of creep feed grinding (CFG) $\gamma$-TiAl, published results highlight the need for reduced operating levels in order to achieve the necessary workpiece integrity, thus compromising productivity $[3,4]$.

The use of ultrasonic (US) vibration ( $>20 \mathrm{kHz}$ frequency) to aid machining appeared in the late 1920's with the development of US assisted grinding following in the 1950's. A comprehensive review of 'hybrid' machining processes including those associated with vibration/US assistance is detailed by Lauwers et al. [5]. The majority of published work on ultrasonic assisted grinding (UAG) has shown significant reductions in grinding forces and benefits in relation to cutting temperature, together with an improvement in workpiece surface integrity [6]. To date, UAG has largely been applied on some ceramics [7], glass and ferrous based materials [8], with only limited literature involving advanced aerospace alloys. In addition, commercial turn-key equipment is scarce. Work on UAG has mainly been associated with surface grinding configurations with depths of cut typically limited to $\leq 0.3 \mathrm{~mm}$. Relatively few papers have reported hybrid ultrasonic assisted creep feed grinding (UACFG) with depths of cut $\geq 1 \mathrm{~mm}[9,10]$. The present research aimed to investigate the effects of US vibration with regard to grinding productivity, wheel wear, cutting forces and workpiece integrity when CFG a $\gamma$-TiAl alloy using conventional and superabrasive wheels.

\section{Experimental details}

Blocks of Ti-45Al-2Mn-2Nb+0.8 vol.\% TiB 2 XD (wt\%) $\gamma$-TiAl alloy $(100 \times 55 \times 7 \mathrm{~mm})$ were used as the workpiece material. This was produced by casting followed by hot isostatic pressing (HIPing) at a temperature of $1480^{\circ} \mathrm{C}$ and pressure of $148 \mathrm{MPa}$ for 4 hours and subsequently heat treated at a temperature of $1050-1080^{\circ} \mathrm{C}$, for 24 hours, giving a bulk hardness of $\sim 365 \mathrm{HV}_{30}$. The material had a nearly fully lamellar structure with parallel plates of $\gamma$-TiAl and $\alpha_{2}-\mathrm{Ti}_{3} \mathrm{Al}$, and a colony size of $\sim 100-130 \mu \mathrm{m}$, see Fig. 1(a). The workpiece was clamped onto a specially designed aluminium table sonotrode/horn connected to an ultrasonic transducer $\sim 20$ $\mathrm{kHz}$ starting frequency linked to a multi-frequency, modulated ultrasonic generator rated at $1 \mathrm{~kW}$. The primary direction of ultrasonic vibration was parallel to that of grinding feed (Y-axis). Under zero-load condition, a maximum amplitude of $8 \mu \mathrm{m}$ was measured using a Laser Doppler Vibrometer.

All grinding trials were carried out on a Bridgeport FGC1000 flexible grinding centre, with a maximum spindle speed of 6000 rpm and power rating of $25 \mathrm{~kW}$. Two high pressure pumping systems were utilised for delivery of grinding fluid via laminar flow nozzles with rectangular cross-sectioned outlets for cooling and cleaning the wheel during grinding [11]. The cooling nozzle orifice $(2 \times 20 \mathrm{~mm})$ was directed towards the grinding zone at an angle and distance of $20^{\circ}$ and $170 \mathrm{~mm}$ respectively, while the cleaning nozzle was aimed tangentially at the periphery on the opposite side of the wheel. Fluid pressure for cooling was 28 bar in order to match or exceed wheel velocity. In contrast, fluid pressure for cleaning was kept constant at 70 bar in all trials. The 
grinding fluid employed was a water based synthetic oil product with a concentration of $\sim 8 \mathrm{vol} \%$. Plain profile vitrified bonded SiC and unconditioned electroplated (EP) diamond superabrasive wheels were utilised. Both wheels had similar average grit size of $\sim 250 \mu \mathrm{m}$ with an outer diameter and width of $220 \mathrm{~mm}$ and 20 $\mathrm{mm}$ respectively. An on-machine configuration of the SiC wheelworkpiece-sonotrode arrangement is shown in Fig. 1(b).

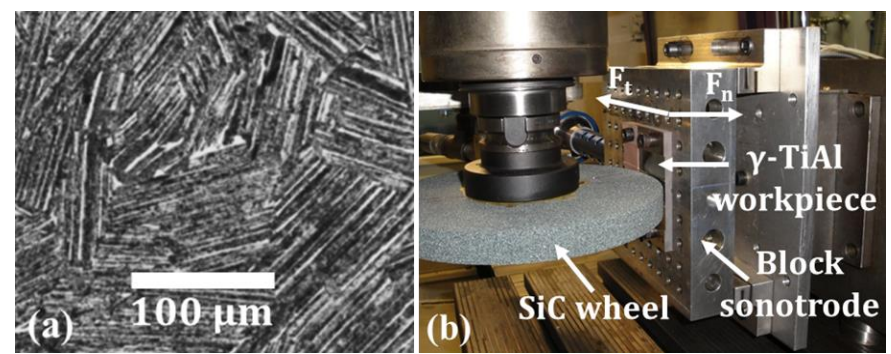

Fig. 1. (a) Microstructure of $\gamma$-TiAl; (b) wheel-workpiece-sonotrode assembly and force directions.

Phase 1 grinding trials involved the $\mathrm{SiC}$ wheel and a full factorial experimental array with 8 tests allowing variations in wheel velocity, $\mathrm{v}_{\mathrm{s}}(15$ and $30 \mathrm{~m} / \mathrm{s})$, table feed, $\mathrm{v}_{\mathrm{w}}(150$ and 600 $\mathrm{mm} / \mathrm{min}$ ) and ultrasonic vibration assistance (US ON and US OFF). Depth of cut per pass, ae was fixed at $1 \mathrm{~mm}$ with all trials performed in a down grinding mode without spark-out. Wheel dressing was carried out prior to each trial using a diamond roller dresser with a $2 \mu \mathrm{m} / \mathrm{rev}$ infeed rate, $50 \mu \mathrm{m}$ dressing depth and 0.8 dresser-to-wheel speed ratio. Phase 2 testing involved use of a superabrasive wheel to assess the influence of ultrasonic actuation. An initial series of 4 tests alternating between conventional CFG and UACFG were undertaken at fixed parameters $\mathrm{v}_{\mathrm{s}}, \mathrm{V}_{\mathrm{w}}$ and $\mathrm{a}_{\mathrm{e}}$ of $30 \mathrm{~m} / \mathrm{s}, 150 \mathrm{~mm} / \mathrm{min}$ and $1 \mathrm{~mm}$ respectively. Two additional tests (US ON and US OFF) were subsequently conducted at increased $\mathrm{v}_{\mathrm{s}}$ and $\mathrm{v}_{\mathrm{w}}$ of $40 \mathrm{~m} / \mathrm{s}$ and 600 $\mathrm{mm} / \mathrm{min}$ respectively. Each test in Phase 1 and 2 involved a single pass of the workpiece (55 mm cut length).

Grinding forces $F_{t}$ and $F_{n}$, see Fig. 1(b), were measured using a Kistler 9257A dynamometer. Grinding-ratio was determined by measuring the wheel diameters before and after each test using a coordinate measuring machine. The wheels were assessed at 30 different points around the periphery, each at 5 different levels of the wheel width. Roughness of the ground workpieces (average of 3 measurements at start, middle and end of slot) was recorded using a stylus based profilometer, with $0.8 \mathrm{~mm}$ cut-off and $4 \mathrm{~mm}$ evaluation length. Wheel surface topography was assessed with a JEOL 6060 SEM by producing positive replicas using a synthetic rubber and resin replicating compound (Microset).

Knoop microhardness depth profile measurements of the $\gamma$-TiAl workpieces were taken using a $25 \mathrm{~g}$ load and indent time of $15 \mathrm{~s}$. Three measurements were recorded, both in the transverse feed (TF) and longitudinal feed (LF) directions, each set at $10 \mu \mathrm{m}$ depth intervals. In order to reveal workpiece microstructures, $\gamma$ TiAl samples were immersion etched in a solution of $2 \%$ hydrofluoric and 10\% nitric acid with balance water for $5 \mathrm{~s}$ and were analysed using a Leica DMLM optical microscope.

\section{Results and discussion}

Figure 2(a) shows that the maximum $\mathrm{F}_{\mathrm{n}}$ varied from $\sim 1450$ to $2300 \mathrm{~N}$ for the vitrified $\mathrm{SiC}$ wheel, with values increasing with cutting speed, the data being comparable to that reported by Hood et al. [4] when creep feed grinding $\gamma$-TiAl at similar process parameters. Analysis of variance (ANOVA) highlighted $v_{s}$ as a significant factor at the $5 \%$ level with a percentage contribution ratio (PCR) of $83 \%$, which was in line with previous work $[4,12]$.
This was attributed to an increase in the sliding length per unit volume of material removed when grinding at higher $\mathrm{v}_{\mathrm{s}}$, which resulted in greater attritious wear and dulling of the abrasive grits leading to higher rubbing and ploughing. Operation under UACFG generally led to lower $F_{n}$, while variation in $v_{w}$ from 150 to $600 \mathrm{~mm} / \mathrm{min}$ had minimal influence (based on tabulated data and corresponding main effects plots not shown here). Conversely, mean $\mathrm{F}_{\mathrm{t}}$, decreased with an increase in $\mathrm{v}_{\mathrm{s}}$ and use of ultrasonic vibration (statistically significant with PCR of $64.5 \%$ ). The application of US actuation generally led to reductions in both $\mathrm{F}_{\mathrm{n}}$ and $\mathrm{F}_{\mathrm{t}}$ by up to $19 \%$ and $35 \%$ respectively, possibly due to selfsharpening of the abrasive grains. Similar results were also presented by Nik et al. [13] when surface grinding Ti-6Al-4V alloy with a vitrified alumina wheel.
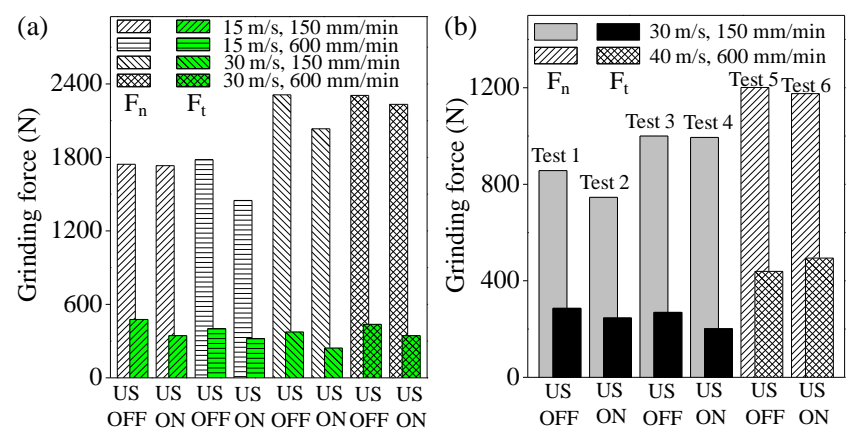

Fig. 2. (a) Grinding forces $\left(F_{n}, F_{t}\right)$ when grinding with $\mathrm{SiC}$ wheel; (b) Grinding forces when using the EP diamond wheel.

In CFG tests with the superabrasive wheel (Tests 1, 3 and 5), $F_{n}$ increased from 857 to $1200 \mathrm{~N}$, the rise of $\sim 150 \mathrm{~N}$ occurring between Test 1 and Test 3 due to cumulative wear of the wheel, see Fig. 2(b). A further increase of $\sim 200 \mathrm{~N}$ between Test 3 and 5 was attributed to the elevated operating parameters $(40 \mathrm{~m} / \mathrm{s}$ and $600 \mathrm{~mm} / \mathrm{min}$ ). Despite the 13\% reduction in $F_{n}$ between Tests 1 (US OFF) and 2 (US ON), the application of ultrasonic vibration appeared to have minimal effect in succeeding tests, possibly due to the different dynamic/mass characteristics of the EP diamond wheel (steel hub) compared to the solid SiC wheel structure. Similarly, it is likely that the variation observed in $\mathrm{F}_{\mathrm{t}}$ was due both to wheel wear and operating parameter variation rather than application of US assistance. With regard to the latter, Zhang and Zhang [14] reported that there is a critical value of feed rate above which the effect of ultrasonic vibration is diminished.

Figure 3(a) shows that the G-ratio of the SiC wheel varied from 3.2 to 8 . This was similar to results by Hood et al. [4] where Gratios between 2 to 15 were obtained when $\mathrm{CFG}$ a slightly different $\gamma$-TiAl alloy of Ti-45Al-8Nb-0.2C wt $\%$ using conventional $\mathrm{SiC}$ abrasives. Except for trials using the highest operating parameters $(30 \mathrm{~m} / \mathrm{s}$ and $600 \mathrm{~mm} / \mathrm{min})$, wheel wear increased (G-ratio reduced) with the rise of both $\mathrm{v}_{s}$ and $\mathrm{v}_{\mathrm{w}}$, while use of UACFG reduced wheel wear. This was most likely due to an increase in attritious wear at a higher cutting speed coupled with larger undeformed chip thickness, $\mathrm{h}_{\mathrm{m}}$ at a greater table feed leading to more frictional forces. The increase in G-ratio $(\sim 30$ to $75 \%$ ) when using US assistance was possibly due in part to a reduction in thermal load. When evaluating the post-grinding wheel surfaces, large voids/loss of grits were typically seen following CFG as shown in Fig. 4(a). Conversely, the wheel surface appeared to be relatively uniform when operating under UACFG with only minor loss of grains, see Fig. 4(b). With uprated operating values, it is likely that the influence of US vibration was negated due to the additional loading on the system.

The comparatively high initial radial wear $(\sim 7 \mu \mathrm{m})$ of the EP diamond wheel after Test 1 under CFG as shown in Fig. 3(b), was due to conditioning of the protruding grits, which is typical with 
new wheels. Wheel wear decreased to only $\sim 2 \mu \mathrm{m}$ in Test 3 as the majority of the protruding grits had undergone micro-fracture above the bond level. Signs of wear flats are shown in Fig. 4(c), however wheel surfaces generally exhibited no visible evidence of chip loading and/or adhered material at the tip of the grits or at inter-grit spaces. The marginal increase in wheel wear following Test 5 was the result of increasing $v_{s}$ to $40 \mathrm{~m} / \mathrm{s}$, which would be expected to generate higher temperatures. Radial wheel wear remained almost negligible $(\sim 1 \mu \mathrm{m})$ in all UACFG trials, aided by the somewhat lower forces under hybrid conditions.
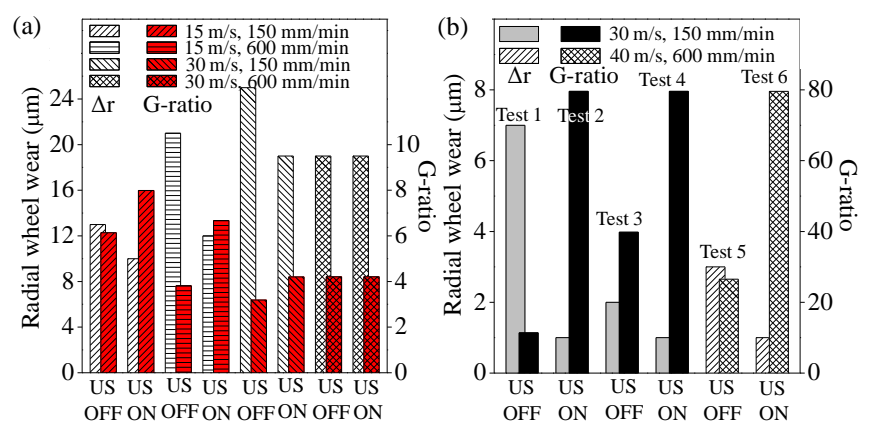

Fig. 3. Radial wheel wear and G-ratio of (a) SiC; (b) diamond wheels.

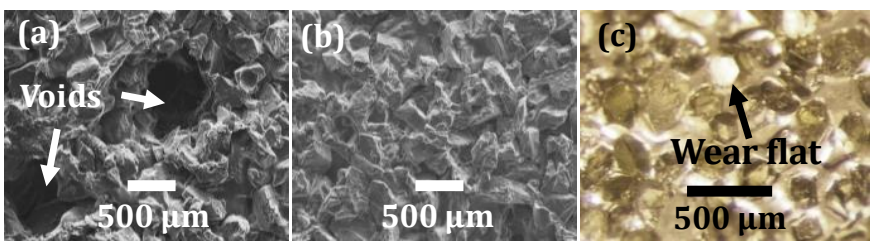

Fig. 4. SEM micrographs of SiC wheel replicas after (a) CFG and (b) UACFG - both at $\mathrm{v}_{\mathrm{s}}=30 \mathrm{~m} / \mathrm{s}, \mathrm{v}_{\mathrm{w}}=150 \mathrm{~mm} / \mathrm{min}$; and (c) optical image of diamond wheel surface indicating a wear flat.

In contrast to the G-ratios obtained with the $\mathrm{SiC}$ wheel $(\sim 3$ to 8 ), the diamond wheel produced higher values, in the range $\sim 11$ 80. With CFG, these varied between $\sim 11$ and 40 , with the lowest value in Test 1 reflecting the high initial radial/conditioning wear. Conversely, the G-ratios remained almost constant at $\sim 80$ under hybrid operation, regardless of operating parameters.

Minor burn and serration marks were observed when grinding with the $\mathrm{SiC}$ wheel at $\mathrm{v}_{\mathrm{s}}=30 \mathrm{~m} / \mathrm{s}, \mathrm{vW}_{\mathrm{W}}=150 \mathrm{~mm} / \mathrm{min}$ and US OFF, most likely due to generation of elevated temperatures when operating at the highest wheel speed, see Fig. 5(a). Work reported by Hood et al. [4] when CFG Ti-45Al-8Nb-0.2C wt\% at a comparable $\mathrm{v}_{\mathrm{s}}$ and $\mathrm{v}_{\mathrm{w}}$ but higher depth of cut $(2.5 \mathrm{~mm})$, details moderate workpiece burn and extensive crack formation, albeit after $24,000 \mathrm{~mm}^{3}$ removed and a relatively low coolant pressure of 7 bar. The use of $\sim 28$ bar in the present study would be expected to lead to greater penetration of fluid into the grinding zone, thereby reducing temperatures. No workpiece burn was visible in any of the current trials with US actuation, see Fig. 5(b).
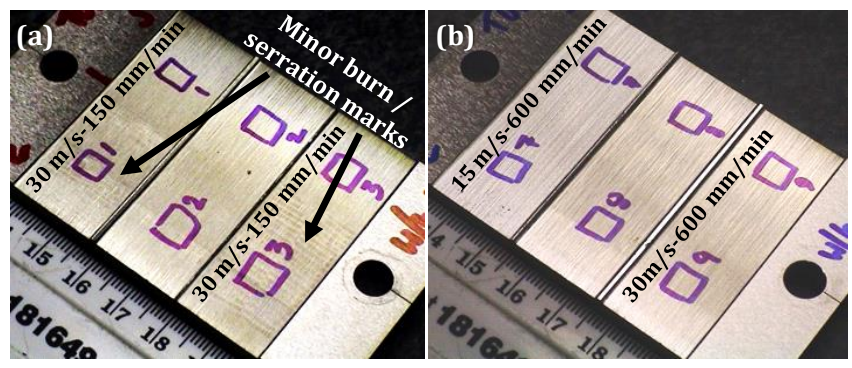

Fig. 5. Images of ground workpieces using $\mathrm{SiC}$ involving; (a) CFG - $30 \mathrm{~m} / \mathrm{s}$, $150 \mathrm{~mm} / \mathrm{min}$, (b) UACFG - 15 and $30 \mathrm{~m} / \mathrm{s}, 600 \mathrm{~mm} / \mathrm{min}$.
High resolution SEM images of the ground surfaces revealed surface fracture and redeposited material on workpieces produced under conventional CFG conditions, see Figs. 6(a) and $6(\mathrm{~b})$. No such damage however was apparent on any of the workpieces subject to UACFG, although greater side flow/ploughing of material and overlapping grit marks were evident on surfaces ground with both types of wheel as detailed in Figs. 6(c) and 6(d). This could have been due to a change in material removal mechanism from a fracture based regime to a ductile mode, as explained by Gao et al. [15] when UAG nanozirconia ceramics. When ultrasonic assisted turning Ti-45Al-2Mn$2 \mathrm{Nb}+0.8 \mathrm{vol} \% \mathrm{TiB}_{2} \mathrm{XD}$, Sharman et al. [16] reported that segmented continuous helical chips up to $25 \mathrm{~mm}$ long were produced in comparison to the more standard needle/discontinuous swarf associated with $\gamma$-TiAl alloys. It was also suggested that reduced cutting force would result in lower tensile stress in the shear zone, thereby reducing crack propagation and growth as normally seen with brittle materials. Additionally, it is feasible that the greater incidence of overlapping grit marks was in part caused by lateral movement of the abrasives [8] under possible multi-modal vibration.

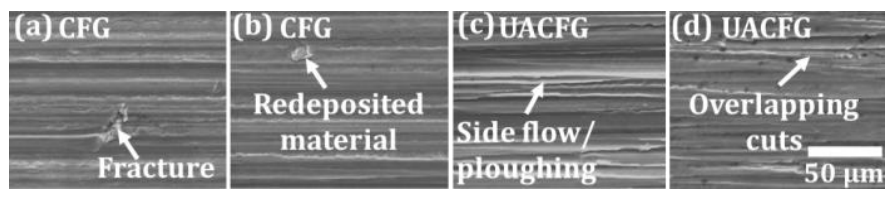

Fig. 6. SEM micrographs of $\gamma$-TiAl surfaces ground using $\mathrm{SiC}$ under (a) and (b) CFG; (c) and (d) UAG conditions.

Average surface roughness $\left(\mathrm{R}_{\mathrm{a}}\right)$ for slots ground with the SiC wheel are shown in Fig. 7(a), which ranged from 1.56 to $2 \mu \mathrm{m} \mathrm{R}$, in line with previous work [4]. Variation in $\mathrm{v}_{\mathrm{w}}$ from 150 to 600 $\mathrm{mm} / \mathrm{min}$ typically caused a rise in $R_{a}$ due to an increase in $h_{m}$, but decreased as $\mathrm{V}_{\mathrm{s}}$ changed from 15 to $30 \mathrm{~m} / \mathrm{s}$ (statistically significant with a PCR of $76.6 \%$ ), due to a reduction of the number of grits in contact with the workpiece surface. Typically $\mathrm{R}_{\mathrm{a}}$ reduced by up to $\sim 10 \%$ when utilising ultrasonic vibration in comparison to that obtained with conventional CFG, which was likely the result of increased active grains as well as overlapping grit trajectories in the former. This was in contrast to the increase in roughness observed when UACFG Inconel $718[9,10]$. This could be attributed to the lamellar microstructure of $\gamma$-TiAl as opposed to the polycrystalline nature of Inconel 718, together with the higher fatigue crack growth rate, lower fracture toughness and impact resistance of $\gamma$-TiAl in comparison to $\mathrm{Ni}$ alloys, resulting in easier material removal from the intermetallic workpieces under the impact-loading action of vibration.
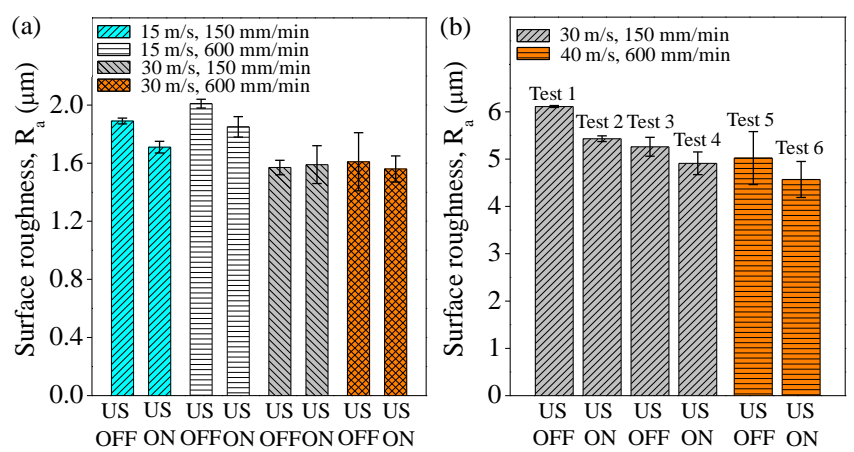

Fig. 7. Roughness $\left(\mathrm{R}_{\mathrm{a}}\right)$ of $\gamma$-TiAl ground with (a) SiC; (b) diamond wheels.

With the EP diamond wheel, significantly higher workpiece roughness values were obtained compared to those with the $\mathrm{SiC}$ wheel due to the initially unconditioned nature of the former. 
Average roughness gradually decreased from Test 1 to Test 4, see Fig. 7(b), due to use and engagement of a greater number of grits in cutting. However, Ra marginally increased in Test 5 due to an increase in $\mathrm{V}_{\mathrm{w}}$, but subsequently decreased following Test 6 , although whether this was a result of further wheel wear/conditioning or micro-splintering of grits caused by US vibration as seen in Phase 1 trials with the $\mathrm{SiC}$ wheel, is unclear.

Figure 8 shows microhardness depth profile data for surfaces in the TF direction ground using the SiC wheel and LF direction ground using the EP diamond wheel. In the former case, maximum near surface (at $\sim 10 \mu \mathrm{m}$ ) hardness ranged up to $\sim 585$ $\mathrm{HK}_{0.025}$, falling to near the bulk hardness after depth of $\sim 200$ to $300 \mu \mathrm{m}$. Similar results have been reported by other authors when CFG $\gamma$-TiAl using SiC wheels $[3,12]$. With ultrasonic assistance, subsurface microhardness typically increased by only $\sim 6-8 \%$, compared to conventional CFG. While the SEM micrographs of surfaces produced with UACFG showed greater ploughing/side flow and smearing of material, see Figs. 6(c) and 6(d), conclusive evidence of significantly increased plastic deformation/strain hardening due to ultrasonic assistance was not apparent in cross-sectional microstructures.
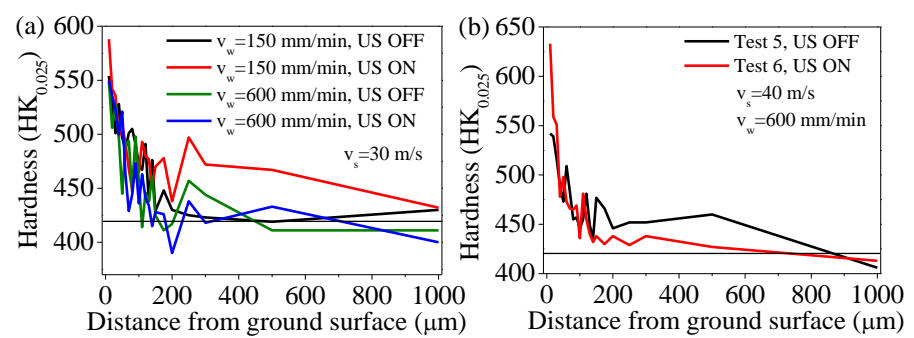

Fig. 8. Microhardness depth profiles of $\gamma$-TiAl in; (a) TF plane, ground using $\mathrm{SiC}$ wheel; (b) LF plane, ground using diamond wheel.

Figure 9(a) details a representative cross-sectional microstructure of the workpiece in the LF direction after UACFG using the $\mathrm{SiC}$ wheel at $\mathrm{v}_{\mathrm{s}}$ and $\mathrm{v}_{\mathrm{w}}$ of $15 \mathrm{~m} / \mathrm{s}$ and $150 \mathrm{~mm} / \mathrm{min}$ respectively. Deformation/bending of the lamellae up to $\sim 10 \mu \mathrm{m}$ beneath the ground surface is visible. Lamellae bending, as anticipated was less pronounced in TF sections (not subject to feed effect) such as that shown in Fig. 9(b), involving a higher cutting speed $30 \mathrm{~m} / \mathrm{s}$, however typical grit marks were visible. Similar trends were observed in workpieces ground using the EP diamond wheel, see Fig. 9(c), but with somewhat higher depth of deformation of up to $\sim 20 \mu \mathrm{m}$ after Test 4 , due to the increased number of active grains as a result of cumulative wheel wear.

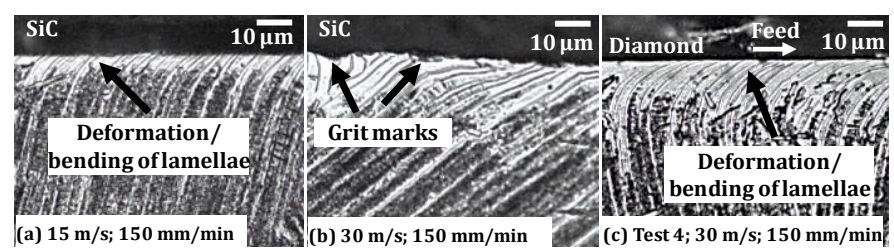

Fig. 9. Microstructures of $\gamma$-TiAl samples after UACFG with $\mathrm{SiC}$ wheel in (a) LF, (b) TF planes; and with diamond wheel in (c) LF plane.

\section{Conclusions}

When UACFG $\gamma$-TiAl, lower grinding forces were generally obtained with both vitrified $\mathrm{SiC}$ and $\mathrm{EP}$ diamond wheels compared to conventional CFG operation. With the former wheel, the normal and tangential components reduced by up to $19 \%$ and $35 \%$ respectively, while for the diamond wheel, values were $13 \%$ and $25 \%$ lower, however with uprated process parameters, the benefits of US assisted operation were less apparent. Similarly, higher wheel G-ratios $(30-75 \%$ for the SiC and $100-625 \%$ for the diamond wheel) and marginally better workpiece surface roughness/quality $\left(\sim 3-10 \%\right.$ reduction in $\left.R_{a}\right)$ were generally observed under hybrid operating conditions. The $\gamma$-TiAl surfaces machined with UACFG displayed greater smearing, side flow/ploughing and overlapping grit marks possibly due to a change in material removal mechanism favouring a more ductile mode. Microhardness variations between conventional CFG and UACFG were minimal as were alterations of workpiece microstructure. The benefits of UACFG were not as significant as detailed in the literature involving US assisted surface grinding and it is likely that use of much higher depths of cut in UACFG hindered the translation of vibration amplitude to the cutting zone. In relation to the experimental configuration employed, ultrasonic vibration through the spindle/wheel would have been preferable in order to minimise the effects of interface damping in the workpiece-table sonotrode setup and also provide greater flexibility/scope with respect to component size/shape/mass.

\section{Acknowledgements}

The authors acknowledge the financial and technical support of the Uni. of Birmingham, Uni. of Glasgow (Prof. M. Lucas and Dr. A.C. Mathieson), Rolls-Royce plc, Element Six, Saint-Gobain Abrasives, Hardinge Machine Tools and MP Interconsulting.

\section{References}

[1] Hood R, Cooper P, Aspinwall DK, Soo SL, Lee DS (2015) Creep feed grinding of $\gamma$ TiAl using single layer electroplated diamond superabrasive wheels. CIRP Journal of Manufacturing Science and Technology 11:36-44.

[2] Aspinwall DK, Dewes RC, Mantle AL (2005) The Machining of $\gamma$-TiAl Intermetallic Alloys. Annals of the CIRP 54/1:99-104.

[3] Bentley SA, Aspinwall DK (1997) The Identification of Significant Operating Parameters When Conventional Abrasive Creep Feed Grinding a Gamma Titanium Aluminide Intermetallic. Proceedings of the 4th International Charles Parsons Turbine Conference, Advances in Turbine Materials, Design and Manufacturing, Newcastle Upon Tyne, UK, 474-488.

[4] Hood R, Lechner F, Aspinwall DK, Voice W (2007) Creep Feed Grinding of Gamma Titanium Aluminide and Burn Resistant Titanium Alloys Using SiC Abrasive. International Journal of Machine Tools and Manufacture 47:14861492.

[5] Lauwers B, Klocke F, Klink A, Tekkaya AE, Neugebauer R, McIntosh D (2014) Hybrid Processes in Manufacturing. CIRP Annals - Manufacturing Technology 63/2:561-583.

[6] Klocke F, Soo SL, Karpuschewski B, Webster JA, Novovic D, Elfizy A, Axinte DA Tönissen S (2015) Abrasive Machining of Advanced Aerospace Alloys and Composites. CIRP Annals - Manufacturing Technology 64/2: 581-604.

[7] Ding K, Fu Y, Su H, Xu H, Cui F, Li Q (2017) Experimental studies on matching performance of grinding and vibration parameters in ultrasonic assisted grinding of $\mathrm{SiC}$ ceramics. International Journal of Advanced Manufacturing Technology, 88(9):2527-2535

[8] Tawakoli T, Azarhoushang B, Rabiey M (2009) Ultrasonic Assisted Grinding of Soft Steel. Industrial Diamond Quarterly 1:40-44.

[9] Bhaduri D, Soo SL, Aspinwall DK, Novovic D, Harden P, Bohr S, Martin D (2012) A Study on Ultrasonic Assisted Creep Feed Grinding of Nickel Based Superalloys. Procedia CIRP 1:359-364.

[10] Bhaduri D, Soo SL, Novovic D, Aspinwall DK, Harden P, Waterhouse C, Bohr S, Mathieson AC, Lucas M (2013) Ultrasonic Assisted Creep Feed Grinding of Inconel 718. Procedia CIRP 6:615-620.

[11] Webster JA (2007) Improving Surface Integrity and Economics of Grinding by Optimum Coolant Application, with Consideration of Abrasive Tool and Process Regime. Proceedings of the Institution of Mechanical Engineers, Part B: Journal of Engineering Manufacture 221(12):1665-1675.

[12] Hood R, Aspinwall DK, Voice W (2007) Creep Feed Grinding of a Gamma Titanium Aluminide Intermetallic Alloy Using SiC Abrasives. Journal of Materials Processing Technology 191:210-214.

[13] Nik MG, Movahhedy MR, Akbari J (2012) Ultrasonic-Assisted Grinding of Ti6Al4V Alloy. Procedia CIRP 1:370-375.

[14] Zhang, H, Zhang J (2009) Separate critical condition for ultrasonic vibration assisted grinding. Journal of Shanghai University 13(5):391-395.

[15] Gao GF, Zhao B, Xiang DH, Kong QH (2009) Research on the Surface Characteristics in Ultrasonic Grinding Nano-Zirconia Ceramics. Journal of Materials Processing Technology 209:32-37.

[16] Sharman ARC, Li XP, Rahman M, Bowen P, Dewes RC, Aspinwall DK (2001) Ultrasonic Assisted Turning of Gamma Titanium Aluminide. Proceedings of the Thirteenth International Symposium for Electromachining - ISEM XIII (Vol. 2), Bilbao, Spain, 939-951. 